\title{
Intraabdominal Ruptured Liver Abscess: Computed Tomography and Clinical Features
}

\author{
Huynh Quang Huy ${ }^{*}$, Le Cong Tri ${ }^{2}$, Le Quang Minh ${ }^{3}$ and Nguyen Quoc Vinh ${ }^{4}$ \\ ${ }^{1}$ Pham Ngoc Thach University of Medicine and HCMC Oncology Hospital, Vietnam \\ ${ }^{2}$ Surgery Department, Cho Ray hospital, Vietnam \\ ${ }^{3}$ Department of Health, Ministry of Public Security, Vietnam
}

${ }^{4}$ General Surgery Department, HCMC Medical and Pharmacy University Hospital, Vietnam

*Corresponding author: Huynh Quang Huy, MD, PhD. Radiology Department, Pham Ngoc Thach University of Medicine and HCMC

Oncology Hospital, Vietnam. 2 Duong Quang Trung street, District 10, Ho Chi Minh city, Vietnam

\begin{tabular}{l}
\hline ARTICLE INFO \\
\hline Received: 幽 May 29, 2019 \\
Published: 㞽 June 10, 2019 \\
\hline Citation: Huynh Quang Huy, Le Cong \\
Tri, Le Quang Minh, Nguyen Quoc Vinh. \\
Intraabdominal Ruptured Liver Abscess: \\
Computed Tomography and Clinical Fea- \\
tures. Biomed J Sci \& Tech Res 18(4)- \\
2019. BJSTR. MS.ID.003197.
\end{tabular}

Keywords: Liver; Abscess; Ruptured; Computed Tomography; Clinical

\section{ABSTRACT}

Objectives: The purpose of this study is to describe the Computed Tomography (CT) and clinical findings of intraabdominal ruptured liver abscess.

Patients and Methods: The computed tomography and clinical findings of 32 patients who had a confirmed intraabdominal ruptured liver abscess were analyzed retrospectively at Cho Ray hospital between 2014 and 2018.

Results: 32 patients with a median age of $53.3 \pm 15.3$ years (range, 24-85 years). There were more men than women in the study, with a male-to-female ratio of 1.9:1. Most of the patients were suffering from abdominal pain (96.9\%), malaise and anorexia (96.9\%), fever (78.1\%), peritonitis (78.1\%). The mean size of the liver abscess was 8.4 $\mathrm{cm}$ (range, 4.0-14 cm). A single abscess was found in 11 patients, and multiple abscesses were seen in 21 patients. Unilobar involvement was seen in 29 patients, with the right lobe affected more commonly $(68.8 \%, 22$ of 32$)$. The abscesses were completely liquefied in 25 patients and gas in the abscess cavity in 7 patients. Free intraperitoneal fluid was seen in all patients.

Conclusion: A knowledge of intraabdominal ruptured liver abscess is important for an early diagnosis and appropriate management.

\section{Introduction}

Liver abscess is a common condition in tropical countries and is associated with significant morbidity and mortality. Traditionally, there are two major classifications of hepatic abscess; pyogenic and amoebic [1,2]. There are various complications associated with hepatic abscesses, of which, rupture of the abscess is the most common [3-5]. Intraperitoneal rupture of liver abscess is a rare but potentially fatal disease, often involving the elderly, who are commonly of poor surgical risk with background of significant medical illness [6,7]. Accurate preoperative diagnosis is difficult and often necessitates exploratory laparotomy for peritonitis [8]. Computed Tomography (CT) is an ideal tool for diagnosing hepatic abscesses, and the sensitivity of CT for detecting hepatic abscesses is as high as $97 \%$ [9]. On CT, an hepatic abscess appears as a single or multiloculated mass with low attenuation [9].

Early diagnosis and prompt therapy are essential to reducing the morbidity and mortality associated with a pyogenic hepatic abscess. The mortality rate is low when the abscess is confined to the liver; however, the mortality rate is increased when the hepatic abscess extends into the chest, peritoneal cavity, or pericardial cavity [10]. Therefore, the early detection of complications associated with hepatic abscesses is important. In hepatic abscess, various complications have been described [11-13] and the rate of complications was reported to be $10.3 \%$ [10]. Reports of complications in pyogenic hepaticabscess are rare, however, and 
the imaging appearance has been studied in only a small number of patients $[13,14]$. This article presents the CT and clinical findings of our patients with intraabdominal ruptured liver abscess.

\section{Patients and Methods}

This is a retrospective observational study of patients with intraabdominal ruptured liver abscess presenting to Cho Ray hospital between 2014 and 2018. The study was approved by the Hospital Ethical Board. All diagnosed cases of ruptured liver abscess based on radiology and laparoscopic investigation were included in the study. Details of demographics, clinical features, Computed Tomography were recorded. Data will be analyzed using SPSS software.

\section{Clinical Parameter}

Demographic and clinical characteristics comprised age, sex, underlying medical conditions (diabetes mellitus, biliary disorders, hemodialysis, liver cirrhosis, malignancy, immunosuppression, cavities from old calcified echinococcus cysts, simple benign liver cysts), symptoms and signs at presentation and origin of the abscess. Patients receiving empiric therapy with antibiotics prior to admission were also recorded.

\section{Liver CT Characteristics}

All patients underwent contrast enhanced CT of the liver before laparoscopic drainage of the liver abscess. In some patients, CT studies were also performed during follow-up to assess the size of the abscess cavity, monitor complications. However, we only reviewed the contrast-enhanced CT images obtained before drainage of the liver abscess, for the purpose of this study. The CT examinations were performed using Somatom Sensation 64, Siemens, Germany. The scanning parameters varied during the study period and with different scanners: collimation ranged from $1.25 \mathrm{~mm}$ to $7 \mathrm{~mm}$; pitch ranged from 0.75 to 1.5 ; section thickness ranged from $1 \mathrm{~mm}$ to $5 \mathrm{~mm}$. Liver examinations were conducted using $100 \mathrm{ml}$ of intravenous non-ionic iodinated contrast medium (Ultravist, Schering, Berlin, Germany) and dosage was calculated based on the patients' weight and administered via a power injector at a rate of $3 \mathrm{~mL} / \mathrm{sec}$.

Axial sections of 3-5 mm thickness were reconstructed, reported, and archived. The scans were reviewed by two radiologists who reached agreement between them. The following features were recorded:

a) Lobe involvement (unilobar [right or left] or bilobar);

b) Number of abscesses (single or multiple);

c) Maximal abscess diameter, with the largest abscess measured when there were multiple abscesses;

d) Unilocular or multilocular (presence of $\geq 1$-mm-thick septations), multilocular abscess;

e) Solid or cystic appearance ( $>50 \%$ of the abscess cavity appears hypodense or liquefied, with an attenuation value of $\leq 20 \mathrm{HU}$ ) in most of the sections showing the abscess cavity, cystic absces;

f) Gas within the abscess cavity;

g) Spontaneous rupture of the abscess (based on CT and clinical symptoms).

\section{Results}

\section{Clinical Features}

The study group consisted of 32 patients with a median age of $53.3 \pm 15.3$ years (range, $24-85$ years). There were more men than women in the study, with a male-to-female ratio of 1.9:1. Diabetes mellitus was the most common underlying medical condition (25.0\%), followed by bacterial pneumoniae (18.8\%), hypertension (6.3\%), bile duct stones (3.1\%) showed in Table 1. Most of the patients were suffering from abdominal pain (96.9\%), malaise and anorexia (96.9\%), fever (78.1\%), peritonitis (78.1\%), and other positive clinical signs showed in Table 2.

Table 1: Underlyung diseases of patients with intraabdominal ruptured liver abscess.

\begin{tabular}{|c|c|c|}
\hline Underlying diseases & Frequency & Percentage (\%) \\
\hline Hypertension & 2 & 6.3 \\
\hline Diabetes mellitus & 8 & 25 \\
\hline Bacterial pneumoniae & 6 & 18.8 \\
\hline Bile duct stones & 1 & 3.1 \\
\hline
\end{tabular}

Table 2: Clinical presentations of intraabdominal ruptured liver absces.

\begin{tabular}{|c|c|c|}
\hline Clinical presentations & Frequency & Percentage (\%) \\
\hline Abdominal pain & 31 & 96.9 \\
\hline Malaise and anorexia & 31 & 96.9 \\
\hline Nausea / vomiting & 20 & 62.5 \\
\hline Fever > 38oC & 25 & 78.1 \\
\hline Jaundice & 5 & 15.6 \\
\hline Peritonitis & 25 & 78.1 \\
\hline Hepatomegaly & 4 & 12.5 \\
\hline
\end{tabular}

\section{Liver CT Characteristics}

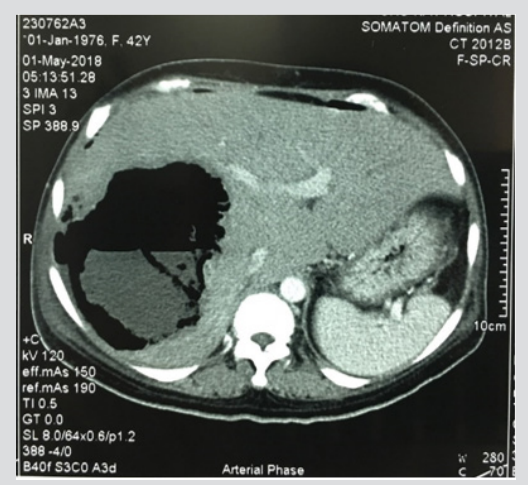

Figure 1: A 42-year-old woman with rupture of a pyogenic hepatic abscess into the peritoneal cavity resulting in peritonitis. The abscess is located in the right hepatic lobe with gas inside. 
The mean time interval between the onset of fever and CT was 8.3 days (range, 1-30 days). The mean size of the liver abscess was $8.4 \mathrm{~cm}$ (range, 4.0-14 cm). A single abscess was found in 11 patients, and multiple abscesses were seen in 21 patients. Unilobar involvement was seen in 29 patients, with the right lobe affected more commonly (68.8\%, 22 of 32). The abscesses were completely liquefied in 25 patients and gas in the abscess cavity in 7 patients. Free intraperitoneal fluid was seen in all patients. The liver CT chracteristics of intraabdominal ruptured liver absces was showed in Table 3 and Figures $1 \& 2$.

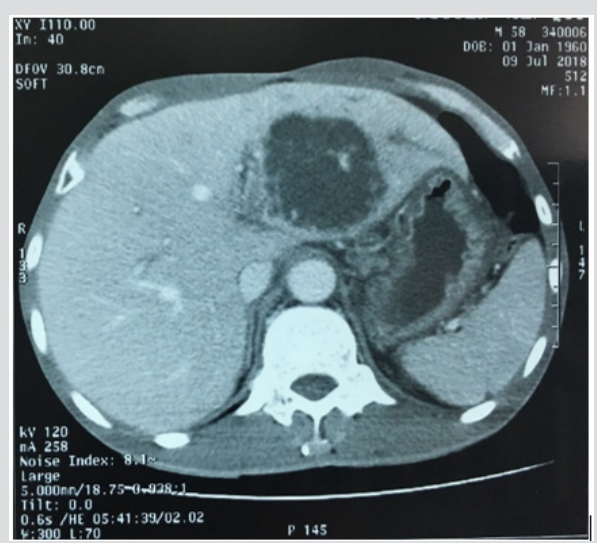

Figure 2: A 62-year-old man rupture of a pyogenic hepatic abscess forming a perihepatic abscess. An enhanced helical computed tomography scan shows a heterogeneously hypodense abscess in the left hepatic lobe.

Table 3: CT chracteristics of intraabdominal ruptured liver absces.

\begin{tabular}{|c|c|}
\hline CT findings & All patients $(\mathbf{n}=\mathbf{3 2})$ \\
\hline Abscess size $(\mathrm{cm})$ & $8.4(4.0-14)$ \\
\hline No. of abscesses & $11(34.4)$ \\
1 & $21(65.6)$ \\
\hline 1 & $29(90.6)$ \\
Unilobar & $3(9.4)$ \\
Bilobar & $25(78.1 \%)$ \\
\hline Abscess appearance & $7(21.9)$ \\
\hline Completely liquefied & $32(100 \%)$ \\
\hline Gas in the abscess cavity & \\
\hline Peritoneal effusion & \\
\hline
\end{tabular}

\section{Discussion}

Liver abscess is an important tropical gastrointestinal disorder $[15,16]$. Liver abscess can be classified into pyogenic and amebic, both having its serious implications, especially when presented late. In developing countries, it forms a major cause for mortality and morbidity $[17,18]$. With the advent of modern radiological modalities, diagnosis of hepatic abscess is possible in early stages resulting in nonsurgical management; however, fraction of patients either due to late presentation or refractory disease presents with ruptured liver abscess thereby increasing the mortality, presents with fatal disease course, and requires surgical intervention at the earliest $[8,19]$. Intraperitoneal rupture is one of the serious complication of liver abscesses [5, 10, 20, 21]. The frequency of intraperitoneal rupture of an liver abscess varies from $2.5 \%$ to $17 \%$ [22]. Clinically, increasing hepatic tenderness should indicate an impending rupture [22].

Computed Tomography may provide important information regarding the extent of intraperitoneal spread of the liver abscess. Dal Mo Yang et al [23] study 81 patients who had a confirmed pyogenic hepatic abscess, the complication was encountered in 3 patients $(3.7 \%)$ and 2 types could be recognized: a loculated perihepatic abscess $(n=2)$ and diffuse peritonitis $(n=1)$. In diffuse peritonitis secondary to rupture of a hepatic abscess, a large amount of ascites and diffuse thickening of the parietal peritoneum could be seen on CT. Although an amebic peritonitis secondary to rupture of a hepatic amebic abscess showed a poor survival rate despite surgical intervention, all the patients with intraperitoneal rupture of the pyogenic hepatic abscess could be treated with percutaneous drainage and antibiotic treatment.

The most common presentation was abdominal pain (96.9\%), malaise and anorexia (96.9\%), fever (78.1\%), peritonitis $(78.1 \%)$, nausea/vomiting (62.5\%), jaundice and hepatomegaly (15.6\% and $12.5 \%$, respectively). This results were comparable to study by Hind S. Alsaif with the most common presentation was fever and/or chills, followed by gastrointestinal symptoms (eg, gastrointestinal upset, diarrhea, vomiting, nausea, discomfort, pain), respiratory symptoms (eg, cough, dyspnea, chest distress), and jaundice [24]. The clinical features of ruptured liver absces according to other studies was summarized in the Table 4.

Table 4: Presentation symptoms according to other studies.

\begin{tabular}{|c|c|c|c|}
\hline Symptoms & Shrikant Perka et al. (2016) [25] & Alexopoulou A et al. (2010) [3] & Mukhopadhyay M et al. (2010) [4] \\
\hline Pain & $100 \%$ & $75.70 \%$ & $83 \%$ \\
\hline Fever & $86.70 \%$ & $96.70 \%$ & $80 \%$ \\
\hline Vomiting & $43.30 \%$ & & $26.40 \%$ \\
\hline Cough / pleurisy & $30 \%$ & & \\
\hline Diarrhea & $53.30 \%$ & $12.10 \%$ & \\
\hline Jaundice & & & \\
\hline
\end{tabular}


The CT appearance of liver abscess is variable and nonspecific. One or more round or oval low-density lesions 2-16 cm in diameter may be seen. The margin of the abscess may be smooth or nodular, and one or more internal septations may be present. An enhancing wall is common but not universal. However, the wall may not be apparent if unen- hanced CT is not performed. Thus, the CT differential diagnosis of amebic liver abscess in the adult includes simple hepatic cyst, infected or hemorrhagic cyst, pyogenic liver abscess, echinococcal cyst, hematoma, biloma, cystic or necrotic hepatic metastasis, undifferentiated embryonal sarcoma, and biliary cystadenoma. In the few cases in which a rim of edema is seen peripheral to the lesion, diagnostic consideration may be limited to inflammatory conditions [26]. A feature of amebic liver abscess that may aid in distinguishing it from other focal hepatic lesions is its tendency to extend beyond the surface of the liver.

Our results of liver CT characteristics were comparable to other studies. Alsaif HS et al showed that the median time interval between the onset of fever and CT was 3 days (range, 1-24 days). The median size of the liver abscess was $7 \mathrm{~cm}$ (range, 1.7-14 cm). A single abscess was found in 95 patients, and multiple abscesses were seen in 36 patients. Unilobar involvement was seen in 100 patients, with the right lobe affected more commonly (55.0\%, 72 of 131). The abscesses were predominantly solid and masslike in 67 patients and cystic in 64 patients. Multilocular appearance of the abscesses was present in 115 patients (87.8\%). Thrombophlebitis was present in 30 patients; pylephlebitis, in three; gas in the abscess cavity, in 17; and pneumobilia, in six. Three patients had both gas in the abscess cavity and pneumobilia [24]. Sutdy by Alexopoulou A et al. the majority (69.7\%) of liver abscess involved the right lobe, they were $5-9 \mathrm{~cm}$ in size (63.6\%) and solitary (75.7\%). Multiple abscesses were observed in $24.2 \%$ of patients. The presence of elevated hemidiaphragm (42.4\%), pleural effusion (18.2\%) and basilar infiltrate $(6 \%)$ in chest radiography was also noted. Liver abcess was accompanied by pylephlebitis in 1 patient.

Gas forming were observed in 4 patients (12.1\%) and loculated subcollections in the abscess in $3(9 \%)$ [3]. A single abscess was found in $54(81.8 \%)$ patients, and multiple abscesses were seen in $12(18.2 \%)$ patients in the study of Chang $\mathrm{Z}$ et al. [27]. Among the patients with multiple abscesses, the average number of lesions per patient was 2.5 - 0.67. Unilobar involvement was seen in $54(81.8 \%)$ patients, and multilocular abscess was present in $50(75.8 \%)$ patients. The abscesses were predominantly solid in 38 (57.6\%) patients and cystic in 28 (42.4\%) patients. Thrombophlebitis was present in 9 (13.6\%) patients, and gas in the abscess cavity was present in 11 patients (16.7\%). There were 4 (6.1\%) patients with liver abscess who experienced a spontaneous rupture of the abscess [27]. A definitive diagnosis of liver abscess requires imaging, with both sonography and CT being useful. Sonography is operatordependent and the operator may have difficulty picking out a small, solitary abscess.
Its sensitivity is around 79\%, compared with $98 \%$ for CT [28], but emergency bedside sonography may be very useful in making a rapid diagnosis. Kim et al. suggested certain CT characteristics suggestive of a Klebsiella abscess, such as a hairball sign or airfluid level [29]. However, while such imaging distinctions may be sought, culture and sensitivity results are the key to choosing the appropriate antibiotics. The advancement in radiologic techniques has been credited with the improvement in mortality rates. Ultrasonography and CT evaluation with contrast remain the radiologic modalities of choice in screening procedures and also can be used as techniques for guiding percutaneous aspiration and drainage. With advancement in multidetector CT scan technology, image quality has improved dramatically, allowing for improved detection. Besides, gallium and technetium radionucleotides can be used in diagnosis.

\section{Conclusion}

A ruptured hepatic abscess is more life-threatening than an unruptured one. A rapid and accurate diagnosis and prompt surgical intervention are essential. Most of the cases had an acute presentation and the right lobe is commonly affected. Pain in the abdomen was the most common symptom which presented in most cases. Computed Tomography is an ideal tool for diagnosing hepatic abscesses and its complications.

\section{Acknowledgment}

The author are grateful to physicians, administrative staff at Cho Ray Hospital for allowing us to undertake this research. LCT and HQH contributed to the conception and design of the project and to data collection, analysis and interpretation, and wrote the initial draft of the manuscript. LQM and NQV contributed to the conception and design of the project, as well as the analysis and interpretation. All authors conducted critical revisions of the manuscript, gave final approval to the submitted paper and agreed to be accountable for all aspects of the work.

\section{References}

1. Akhondi H, Sabih DE (2019) Liver Abscess. StatPearls.

2. Chia DWJ, Kuan WS, Ho WH, Sim TB, Chua MT (2019) Early predictors for the diagnosis of liver abscess in the emergency department. Intern Emerg Med.

3. Alexopoulou A, Dimopoulou H, Soultati A, Panetsos G, Dourakis SP (2010) Factors related to complications and mortality in pyogenic liver abscesses. Annals of Gastroenterology 23(4): 296-301.

4. Mukhopadhyay M, Saha AK, Sarkar A, Mukherjee S (2010) Amoebic liver abscess: presentation and complications. Indian J Surg 72(1): 37-41.

5. Satish KR, Sathyanarayana BA, Madhu SL, Nataraj NR, Amit GM, et al. (2015) A study of predictors for identification of risk of complications in patients with liver abscess. Trop Gastroenterol 36(2): 96-100.

6. Elechi EN, Etawo SU (1991) Management of intraperitoneal rupture of amoebic liver abscess: a 6-year experience with 11 cases in Port Harcourt, Nigeria. Trop Doct 21(1): 43-44.

7. Sarda AK, Bal S, Sharma AK, Kapur MM (1989) Intraperitoneal rupture of amoebic liver abscess. Br J Surg 76(2): 202-203. 
8. Memon AS, Siddiqui FG, Memon HA, Ali SA (2010) Management of ruptured amoebic liver abscess: 22-years experience. J Ayub Med Coll Abbottabad 22(2): 96-99.

9. Halvorsen RA, Korobkin M, Foster WL, Silverman PM, Thompson WM (1984) The variable CT appearance of hepatic abscesses. AJR Am Roentgenol 142(5): 941-946.

10. Munoz LE, Botello MA, Carrillo O, Martinez AM (1992) Early detection of complications in amebic liver abscess. Arch Med Res 23(2): 251-253.

11. Mondragon Sanchez R, Cortes Espinoza T, Sanchez Cisneros R, Parra Silva H, Hurtado Andrade H (1994) Rupture of an amebic liver abscess into the pericardium. Presentation of a case and review of current management. Hepatogastroenterology 41(6): 585-588.

12. Mowji PJ, Cohen AJ, Potkin B, Viltuznik J (1987) Amebic liver abscess with hepatoduodenal fistula. Am J Gastroenterol 82(6): 558-559.

13. Tandon N, Karak PK, Mukhopadhyay S, Kumar V (1991) Amoebic liver abscess: rupture into retroperitoneum. Gastrointest Radiol 16(3): 240 242.

14. Yamada S, Maruo H, Mori K, Kosaka A (1996) An unusual case of pyogenic hepatic abscess rupturing into the pericardial cavity. Nihon Kyobu Geka Gakkai Zasshi 44(11): 2072-2075.

15. Cook GC (1991) Gastroenterological emergencies in the tropics. Baillieres Clin Gastroenterol 5(4): 861-886.

16. Reeder MM (1975) Tropical diseases of the liver and bile ducts. Semin Roentgenol 10(3): 229-243.

17. Blessmann J, Van Linh P, Nu PA, Thi HD, Muller Myhsok B, et al. (2002) Epidemiology of amebiasis in a region of high incidence of amebic liver abscess in central Vietnam. Am J Trop Med Hyg 66(5): 578-583.

18. Kannathasan S, Murugananthan A, Kumanan T, De Silva NR, Rajeshkannan $\mathrm{N}$, et al. (2018) Epidemiology and factors associated with amoebic liver abscess in northern Sri Lanka. BMC Public Health 18(1): 118.

19. Short M, Desai AP (2008) Laparoscopy and transdiaphragmatic thoracoscopy in management of ruptured amebic liver abscess. J Laparoendosc Adv Surg Tech A 18(3): 473-476.

\section{ISSN: 2574-1241}

DOI: 10.26717/BJSTR.2019.18.003197

Huynh Quang Huy. Biomed J Sci \& Tech Res

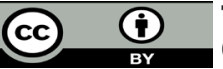

This work is licensed under Creative Commons Attribution 4.0 License

Submission Link: https://biomedres.us/submit-manuscript.php
20. Adams EB, MacLeod IN (1977) Invasive amebiasis. II. Amebic liver abscess and its complications. Medicine (Baltimore) 56(4): 325-334

21. Jolobe OM (2010) Intrahepatic expansion of amebic liver abscess can also generate life-threatening complications. South Med J 103(11): 1189-1190.

22. Eggleston FC, Handa AK, Verghese M (1982) Amebic peritonitis secondary to amebic liver abscess. Surgery 91(1): 46-48.

23. Yang DM, Kim HN, Kang JH, Seo TS, Park CH, et al. (2004) Complications of pyogenic hepatic abscess: computed tomography and clinical features. J Comput Assist Tomogr 28(3): 311-317.

24. Alsaif HS, Venkatesh SK, Chan DS, Archuleta S (2011) CT appearance of pyogenic liver abscesses caused by Klebsiella pneumoniae. Radiology 260(1): 129-138.

25. Perka S, Khajanchi M, Pothare A, Nandu V (2016) Audit of patients with ruptured amoebic liver abscess and outcome of surgical versus nonsurgical treatment. International Surgery Journal 3(4): 2163-2166.

26. Gabata T, Kadoya M, Matsui O, Kobayashi T, Kawamori Y, et al. (2001) Dynamic CT of hepatic abscesses: significance of transient segmental enhancement. AJR Am J Roentgenol 176(3): 675-679.

27. Chang Z, Zheng J, Ma Y, Liu Z (2015) Analysis of clinical and CT characteristics of patients with Klebsiella pneumoniae liver abscesses: an insight into risk factors of metastatic infection. Int J Infect Dis 33: 50 54.

28. Pearl R, Pancu D, Legome E (2005) Hepatic abscess. J Emerg Med 28(3): 337-339.

29. Kim SB, Je BK, Lee KY, Lee SH, Chung HH, et al. (2007) Computed tomographic differences of pyogenic liver abscesses caused by Klebsiella pneumoniae and non-Klebsiella pneumoniae. J Comput Assist Tomogr 31(1): 59-65

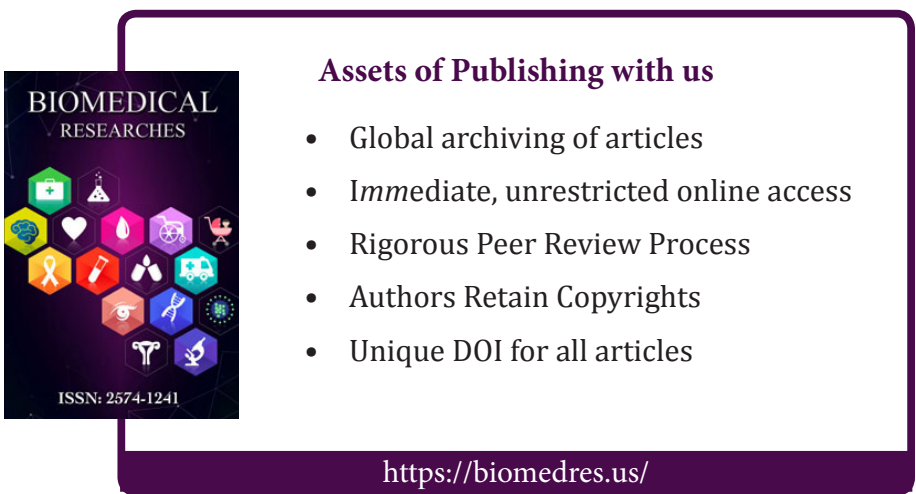

